\title{
Urothelial Papilloma
}

National Cancer Institute

\section{Source}

National Cancer Institute. Urothelial Papilloma. NCI Thesaurus. Code C3842.

A rare benign condition, characterized by a papillary growth in the urinary tract with a central fibrovascular core. The latter is lined by normal urothelium. 